\title{
Effects of Variable Frequencies of Combined Proprioceptive and Kinesthesia, Balance and Agility Exercise Program in Adults With Knee Osteoarthritis: a Study Protocol for Randomized Controlled Trial
}

\section{Aysha I. Adhama}

Bayero University College of Health Sciences

Mukadas 0. Akindele

Bayero University College of Health Sciences

Aminu A. Ibrahim ( $\nabla$ amenconafs@gmail.com )

Bayero University Kano https://orcid.org/0000-0002-5711-1639

\section{Study protocol}

Keywords: Knee osteoarthritis, Kinesthesia, balance and agility exercise, Knee stability, Pain, Physical function, Proprioception, Proprioceptive exercise, Quality of life

Posted Date: May 21st, 2020

DOI: https://doi.org/10.21203/rs.3.rs-28963/v1

License: (9) This work is licensed under a Creative Commons Attribution 4.0 International License. Read Full License

Version of Record: A version of this preprint was published at Trials on July 21st, 2021. See the published version at https://doi.org/10.1186/s13063-021-05386-3. 


\section{Abstract}

Background:Knee osteoarthritis (OA) is a common painful and disabling condition that affects older individuals. Proprioceptive (PR) and kinesthesia, balance and agility (KBA) exercises are two neuromuscular training reported to be beneficial for individuals with knee OA. However, their combined effects have not been systematically evaluated. Moreover, the most optimal dosage of knee OA exercisebased programremains unclear. The aim of this study is to determine the combined effects of PR and KBA exercise program with different frequency of treatment sessions(i.e. twice weekly or thrice weekly) in adults with knee OA.

Methods:A single (assessor) blind, three-arm parallel, multi-centerrandomized controlled trial will be conducted. Eighty-four adults with knee OA will be recruited from four tertiary hospitals in Northwestern Nigeria and randomly assigned into one of three intervention groups; group 1 (control or conventional physiotherapy; $n=28$ ), group 2 (two sessions per week of combined PR and KBA exercise; $n=28$ ), and group 3 (three sessions per week of combined PR and KBA exercise, $n=28$ ). Participants in the conventional therapy group will receive two sessions of brief patient education, and 16 sessions of ultrasound therapy, and stretching, strengthening and aerobic exercise for 8 weeks. Participants in the two experimental groups will be treated for 8 weeks and will also receive the same conventional therapy. All groups will be assessed pre-intervention, immediately post-intervention and at 3-month, 4-month and 6-month post-randomization. The primary outcomes will be physical function and quality of life while the secondary outcomes will be pain intensity, knee stability and proprioception.

Discussion:Findings of this study may provide evidence of effectiveness of combined PR and KBA exercise program for knee $\mathrm{OA}$, which may serve as a basis for recommending the use of such multimodal exercise approachfor individuals with knee OA. The study may also provide evidence for the ideal number of sessions of knee OA exercise-based programsto achieve the highest effectiveness.

Trial registration:Pan African Clinical Trials Registry, (PACTR201810713260138), Registered on 28 November 2017.

\section{Background}

Osteoarthritis $(\mathrm{OA})$ is a common chronic degenerative joint disorder that affects people particularly the older population [1]. It is considered as a disorder of dynamic pathology typified by progressive loss of articular cartilage, subchondral bone sclerosis, cyst and osteophyte formation [2]. The impact of OA is multifactorial including pain, reduced function, quality of life, and increased healthcare and socioeconomic burden [3-5]. OA is the leading cause of disability in the US and worldwide [6]. About 250 million people are currently affected by $O A$ and the prevalence and burden of this disorder is expected to rise globally over the coming decades perhaps due to combined effects of aging and obesity epidemic, along with increasing numbers of joint injuries [3]. 
The knee is one of the most commonly affected joints and accounts for the majority of disability from OA particularly in the elderly [7]. It has been reported that 14 million US populations have symptomatic knee $\mathrm{OA}$, and more than half of these individuals are less than 65 years old [8]. Although data on the prevalence of knee OA in Africa is somewhat sparse [9], numerous hospital-based studies in Nigeria have indicated that knee OA is common [10-14], with prevalence rates of $19.6-20.6 \%$ in people $\geq 40$ years old $[10,11]$ and $16.3 \%$ in people $\leq 30$ years old [11]. Moreover, female gender, obesity, advanced age, knee malalignment, previous knee injury and decreased quadriceps strength [11, 13-15] appears to be the common risk factors associated with knee $O A$ as found in the western nations $[5,16,17]$.

Knee OA presents a major health problem to the society as it accounts for more walking disability than any other condition [18]. Though to date, no specific cure for OA exists, evidence-based approaches including pharmacological, non-pharmacologic and surgical modalities are targeted at reducing symptoms, minimizing functional disability and limiting disease progression [19]. Sufficient evidence suggests that exercise therapy, even though effects are modest, is beneficial for individuals with knee OA $[20,21]$, thus universally endorsed by current guidelines [22-27]. The most recent systematic review and meta-analysis found high-quality evidence that land-based exercise programs provide positive benefits for pain and quality of life and moderate-quality evidence of improved functional disability in individuals with knee OA [20]. While several forms of exercise interventions for this disabling condition exist, most conventionally fall into strengthening, aerobic, flexibility and skills/balance or proprioceptive exercise [28].

Proprioceptive (PR) exercise is a form of neuromuscular training used to manage individuals with knee OA with the goal of improving joint proprioceptive acuity and dynamic stability [29] as these components are commonly altered in these individuals [30-33]. Previous studies suggest that the use of PR exercise program may positively affect postural control, functional capacity, aerobic fitness, joint range of motion and proprioception while reducing knee pain among individuals with bilateral knee OA [34-38]. Moreover, evidence from current systematic and literature reviews suggest that PR training performed in both weight-bearing and non-weight bearing positions may be effective at improving not only proprioceptive accuracy (both position and motion sense) but also pain, function and quality of life $[29,39,40]$.

Kinesthesia, balance and agility (KBA) exercise is another neuromuscular training that has been gaining interest among researchers in the management of knee OA. This form of exercise program is typically designed to improve dynamic joint stability and neuromuscular control using a series of physical activities that challenge the individual's neuromuscular system to maintain balance and coordination [41]. Importantly, results of previous randomized controlled trials (RCTs) indicate that KBA exercise is efficacious for improving pain, function, quality of life, knee stability and physical performance among individuals with knee OA [41-44].

Although PR and KBA exercise demonstrate promising benefits for sufferers of knee OA when used as stand-alone interventions, no previous RCT however has attempted to examine their combined effects in stepped approach. Moreover, the question of what is the ideal number of sessions (dosage) of knee OA exercise-based program can be expected to produce desired therapeutic outcomes remains to be 
elucidated. It is conceivable that the small to moderate effect sizes detected in exercise-based RCTs on knee OA may be due to insufficient dose used [20]. In fact, a recent meta-analysis suggests that evidencebased PR training should consider training frequency of 3 to 4 times per week, for 30 to 40 minutes per session to achieve the highest effectiveness [39]. Thus, this study will be conducted to determine the effects of combined PR and KBA exercise program with different weekly frequencies of application (i.e. twice weekly or thrice weekly) in adults with knee OA. The primary outcomes will be physical function and quality of life whereas secondary outcomes will be pain intensity, knee stability and proprioception. We hypothesized that patients receiving a program of combined PR and KBA exercise would exhibit superior improvements in all outcomes compared to those receiving conventional physiotherapy program for knee $\mathrm{OA}$. Also, patients receiving three sessions per week of combined combined PR and KBA exercise program would demonstrate superior outcomes than those receiving two sessions per week of the same exercise program.

\section{Methods}

\section{Study design}

This study will be a single (assessor) blind, three-arm parallel, multi-center RCT. The outline of the study is shown in Fig. 1. The protocol for this study is reported in accordance with the Standard Protocol Items: Recommendations for Interventional Trials (SPIRIT) 2013 Checklist (Additional file 1).

\section{Study setting}

The study will be conducted at four tertiary hospitals in Kano, Kano State, Northwestern Nigeria; Muhammad Abdullahi Wase Teaching Hospital (MAWTH), Murtala Muhammad Specialist Hospital (MMSH), Aminu Kano Teaching Hospital (AKTH) and National Orthopedic Hospital, Dala (NOHD).

\section{Training of physiotherapists/research assistants}

Prior to the commencement of the study, two licensed physiotherapists with at least two years of clinical experience will be recruited as research assistants in each of the four hospitals. One physiotherapist will be responsible for eligibility and outcome (baseline and follow-up) assessments. This physiotherapist will be blinded to group allocation. The other physiotherapist will be responsible for treatment. All the physiotherapists will receive a two-day training on the study procedures.

\section{Participants' recruitment and eligibility}

Participants for this study will be consecutive patients with knee OA referred to the physiotherapy outpatient unit by the general practitioners in the four tertiary hospitals. Recruitment adverts using local posters with contact of the primary investigator will be pasted at various notice boards in the selected hospitals. To be eligible for the study, participants must meet the clinical criteria for the diagnosis of knee OA according to American College of Rheumatology (ACR) criteria for unilateral or bilateral symptomatic knee OA [45] in addition to being male or female of 30-65 years old. They will be excluded if they have 
any history of knee, hip or ankle surgery prior to the study, peripheral vascular disease, local or systemic infection, deformity in lower limbs, rheumatic disease other than OA, high-risk health status for exercise, unresolved balance or neurological disorder and received intra-articular joint injection within 4 weeks of beginning the study or history of a lower extremity exercise program for a minimum of six weeks prior to enrollment.

\section{Baseline assessment}

Physiotherapists at each of the physiotherapy out-patient unit of the selected hospitals will assess potential participants against the eligibility through clinical history, physical examination, and review of self-report questionnaires. After ensuring eligibility, participants will be given oral and written information regarding the procedures and potential risks of the study. Also, they will be given the option to take part and can withdraw from the study at any time should they choose to do so. Written informed consent will be then sought and obtained. Baseline socio-demographic and clinical variables such as age, gender, marital status, education level, occupational status, height, weight, body mass index, duration of knee pain and side affected will be collected using a prepared proforma. Baseline self-report clinical outcome assessments include; pain, physical function, quality of life and knee stability. Baseline objective outcome measure will be proprioception measurement. The flow of participants is depicted in Fig. 2 .

\section{Randomization and allocation concealment}

After completing the baseline assessment, the participants will be randomized into three study groups in the ratio of 1:1:1. Simple randomization using a fishbowl technique will be carried out in each of the study centers by a third party, who will be completely blinded of the study content. The randomization will be achieved by the means of sealed envelopes, which will be prepared in advance and marked inside with letters $\mathrm{A}$ or $\mathrm{B}$ or $\mathrm{C}$, representing group 1 (i.e. control or conventional physiotherapy), group 2 (i.e. two session per week of combined PR and KBA exercises) and group 3 (i.e. three session per week of combined PR and KBA exercises), respectively. A participant will be asked to pick an envelope from the bowl without replacement and when opened, the group written on the paper inside determines the intervention the participant will receive. Every new participant that met the inclusion criteria in each of the four research centers will be consecutively recruited and randomly assigned to any of the three groups in the same way until the required sample size is met.

\section{Blinding}

The outcome assessors (physiotherapists) in this study will be blinded to the group allocation and will not be involved in administering the interventions. The participants will be told they are in a "conventional physiotherapy" or the "two sessions per week of combined PR and KBA exercise" or "three sessions per week of combined PR and KBA exercise" but the type of intervention (electrotherapy or exercise or both) will not be specified. Conversely, due to the nature of the interventions, it will be difficult to blind the physiotherapists to providing the treatments. Unbinding conditions will be only permissible when there is medical emergency. 


\section{Interventions}

Participants in group 1 (control group) will receive a conventional physiotherapy program consisting of brief patient education, ultrasound therapy, stretching, strengthening and aerobic exercises. The program will be delivered twice weekly for 8 weeks except for the education program which will be provided in two sessions. The stretching exercises will be performed as warm-up and cool-down. Participants in group 2 will receive two sessions per week of combined PR and KBA for 8 weeks while participants in group 3 will receive three sessions per week of the same exercise program as for group 2. Both group 2 and 3 will receive the same conventional physiotherapy program as described for the group 1 prior to receiving the combined PR and KBA exercise program. All interventions will be delivered individually under the supervision of the treating physiotherapists. All participants will be encouraged to perform exercises consistent with their group allocation at least 2 times per day at home. A leaflet containing descriptions and pictures of their home exercises will be given to the participants to encourage adherence.

\section{Brief patient education}

Prior to exercise interventions, the participants will receive a brief education lasting approximately $15-20$ minutes. The program will be delivered by the therapists responsible for exercise interventions. It will be provided in a group of 4-5 or more patients to save effort. The key topics to be addressed include: (1) understanding of knee OA, (2) lifestyle and physical activity/exercise, (3) diet and weight control, (4) selfmanagement skills including active coping and pacing as well as correct use of medications (e.g. paracetamol), and (5) ergonomics and joint protection.

\section{Ultrasound therapy (UST)}

The affected knee of the participants will be treated with UST using the direct contact technique. A coupling medium (ultrasonic gel) will be used. The treatment parameters to be used include; frequency = $1 \mathrm{MHZ}$, pulse duration $=2.0 \mathrm{~W} / \mathrm{cm}^{2}$, pulse rest time $=1: 1$ (continuous mode), and duration $=7$ minutes . The UST will precede the stretching and strengthening exercise program.

\section{Stretching, strengthening and aerobic exercise}

Participants will perform 3 lower-extremity stretching and strengthening exercises commonly prescribed for individuals with knee OA as described in previous studies $[44,46]$. The stretching includes; hamstring stretch, quadriceps stretch and calf stretch for each limb. The stretching will be repeated as cool-down after completing the strengthening exercises.

Following the stretching, the participants will be instructed to perform the strengthening exercises including static quadriceps isometric, knee extension and leg curl exercise. Each exercise will be held for 15 seconds and repeat 6 times. Progression will be made by increasing the number of sets from 15 seconds hold to 30 seconds hold when the 15 seconds hold is no longer challenging, and the patient is performing activity with ease and good form. However, the exercise will be discontinued if the patient 
reports an exacerbation of symptoms. The details of the stretching and strengthening exercise protocol are presented in Table 1.

Table 1

Stretching and strengthening exercise program

\begin{tabular}{|c|c|c|c|}
\hline \multicolumn{4}{|c|}{ Stretching exercise program } \\
\hline Exercise & Description & $\begin{array}{l}\text { Warm- } \\
\text { up }\end{array}$ & $\begin{array}{l}\text { Cool- } \\
\text { down }\end{array}$ \\
\hline $\begin{array}{l}\text { 1.Hamstring } \\
\text { stretch }\end{array}$ & $\begin{array}{l}\text { Patient positioned in supine and keeps the knees and hips at 90- } \\
90 \text { degrees position. The knee of one leg is then, extended } \\
\text { progressively with the foot moving towards ceiling until it is } \\
\text { perpendicular to the floor. Switch sides. }\end{array}$ & $\begin{array}{l}15 \mathrm{~s} \\
\text { hold, } \\
6 \text { reps }\end{array}$ & $\begin{array}{l}15 \text { s } \\
\text { hold, } \\
6 \\
\text { reps }\end{array}$ \\
\hline $\begin{array}{l}\text { 2.Quadriceps } \\
\text { stretch }\end{array}$ & $\begin{array}{l}\text { Patient positioned in side-lying and grasps the forefoot behind. } \\
\text { The forefoot or ankle is pulled to rear end. Switch sides. }\end{array}$ & $\begin{array}{l}15 \mathrm{~s} \\
\text { hold, } \\
6 \text { reps }\end{array}$ & $\begin{array}{l}15 \text { s } \\
\text { hold, } \\
6 \\
\text { reps }\end{array}$ \\
\hline $\begin{array}{l}\text { 3.Calf } \\
\text { stretch }\end{array}$ & $\begin{array}{l}\text { Patient sits with the legs straight out in front. One leg is bend and } \\
\text { a towel is placed around the ball of the opposite foot. While } \\
\text { keeping the knee straight, pull the foot towards the body with the } \\
\text { towel. Switch sides. }\end{array}$ & $\begin{array}{l}15 \mathrm{~s} \\
\text { hold, } \\
6 \text { reps }\end{array}$ & $\begin{array}{l}15 \text { s } \\
\text { hold, } \\
6 \\
\text { reps }\end{array}$ \\
\hline
\end{tabular}

Strengthening exercise program

Exercise Description

Intensity

1.Static Patient stands with one leg straight and the knee of the opposite $\begin{array}{ll}\text { quadriceps leg flexed, and the foot flat on the ground. A rolled towel or a } \\ \text { isometrics } & \text { cushion is placed underneath the straight leg's knee. The straight }\end{array}$

15 s hold, 6 cushion is placed underneath the straight leg's knee. The straight reps sides.

2.Seated Patient sits on a chair with one foot flat on the floor and knee straightens the opposite foot. Switch sides.

15 s hold, 6 reps

extension

3. Lying leg Patient lies prone and squeezes the inner thigh to keep the legs curl close next to each other. The legs are then bend as far as possible by bringing the heels in towards the buttocks.

15 s hold, 6 reps

The current guidelines consistently recommend low to moderate impact aerobic activity for individuals with $O A[47,48]$. Considering this recommendation, participants will be advised to perform aerobic exercise (for example continuous outdoor walking or biking) at low to moderate intensity or tolerable speed for 20-30 minutes, 3-4 times per week at home.

\section{Combined proprioceptive and kinesthesia, balance and agility exercise program}

The exercise regimen of combined PR and KBA will be done by performing a series of proprioceptive, balance and walking agility exercises (Table 2). The PR and KBA exercise program was adapted from the 
program described by Mondam et al. [37] and Rogers et al. [44], respectively. Progression of exercise will be considered based on the participant's ability. The exercise program will last for approximately $30-40$ minutes per session. The details of the exercise program are presented in Table 2.

Table 2

Combined proprioceptive and kinesthesia, balance and agility exercise program

\begin{tabular}{|c|c|c|}
\hline Exercise & Description & Timing \\
\hline $\begin{array}{l}\text { 1.One-leg } \\
\text { balance on } \\
\text { hard surface }\end{array}$ & $\begin{array}{l}\text { Patient stand on one-leg with relaxed, upright posture. The opposite leg is } \\
\text { bent at knee, hip and ankle. The position is held for } 1 \text { minute, followed by } \\
\text { rest for } 10-20 \text { seconds and repeated twice. Rest for } 1-2 \text { minutes and } \\
\text { switch sides. }\end{array}$ & $6 \min$ \\
\hline $\begin{array}{l}\text { 2.Blind } \\
\text { advanced one- } \\
\text { leg balance on } \\
\text { hard surface }\end{array}$ & $\begin{array}{l}\text { Following the same guidelines for one-leg balance, keep eyes closed. } \\
\text { Rest for } 1-2 \text { minutes and switch sides. }\end{array}$ & $6 \min$ \\
\hline $\begin{array}{l}\text { 3.Toe walking } \\
\text { on hard } \\
\text { surface }\end{array}$ & $\begin{array}{l}\text { Patient walk for a } 20 \text { meter distance with the toes pointing straight } \\
\text { ahead and then walk with toes pointing out. Rest for } 1-2 \text { minutes and } \\
\text { switch sides. }\end{array}$ & $2 \min$ \\
\hline $\begin{array}{l}\text { 4.Cross body } \\
\text { leg swings }\end{array}$ & $\begin{array}{l}\text { Patient leans slightly forward with hands on a wall for support and } \\
\text { weight on one leg. Swing the opposite leg in front of the body. Repeat } 15 \\
\text { times. Rest for 1-2 minutes and switch sides. }\end{array}$ & $45 \mathrm{~s}$ \\
\hline $\begin{array}{l}\text { 5.Side } \\
\text { stepping }\end{array}$ & $\begin{array}{l}\text { Patient stands with feet together and move one leg laterally and then } \\
\text { brought back to original position. Start with } 15 \text { steps and progress to } 75 \\
\text { steps. Rest for } 1-2 \text { minutes and switch sides. }\end{array}$ & $60 \mathrm{~s}$ \\
\hline $\begin{array}{l}\text { 6.Semi- } \\
\text { tandem walk }\end{array}$ & $\begin{array}{l}\text { Patient walk heel-to-toe with heel landing just in front of and medial to } \\
\text { great toe of opposite foot. Start with } 15 \text { steps and progress to } 75 \text { steps. } \\
\text { Rest for } 1-2 \text { minutes and switch sides. }\end{array}$ & $\begin{array}{l}1 \mathrm{~min} \\
30 \mathrm{~s}\end{array}$ \\
\hline $\begin{array}{l}\text { 7.Cross-over } \\
\text { walk }\end{array}$ & $\begin{array}{l}\text { Patient walk forward by bringing each foot across midline of body. Start } \\
\text { with } 15 \text { steps and progress to } 75 \text { steps. Rest for } 1-2 \text { minutes and switch } \\
\text { sides. }\end{array}$ & $\begin{array}{l}1 \mathrm{~min} \\
30 \mathrm{~s}\end{array}$ \\
\hline $\begin{array}{l}\text { 8.Balance on } \\
\text { foam (double- } \\
\text { leg static) }\end{array}$ & $\begin{array}{l}\text { Patient instructed to stand steady as long as possible (up to the } 30 \\
\text { seconds limit). }\end{array}$ & $2 \min$ \\
\hline $\begin{array}{l}\text { 9.Balance on } \\
\text { foam (single- } \\
\text { leg static) }\end{array}$ & $\begin{array}{l}\text { Patient stands with single-leg support and the therapist attempts to } \\
\text { perturb the patient's balance in various directions for } 10-30 \text { seconds. } \\
\text { Rest for } 1-2 \text { minutes and switch sides. }\end{array}$ & $2 \min$ \\
\hline $\begin{array}{l}\text { 10.Balance on } \\
\text { foam } \\
\text { (dynamic) }\end{array}$ & $\begin{array}{l}\text { Patient stands on foam and is instructed while performing small, rapid } \\
\text { bouncing movements but without jumping. Patient instructed to flex and } \\
\text { extend the knee to about } 5-10 \text { degrees maximum. }\end{array}$ & $2 \min$ \\
\hline $\begin{array}{l}\text { 11.Multiple } \\
\text { change in } \\
\text { direction drill }\end{array}$ & $\begin{array}{l}\text { Therapist provides hand signals directing the patient to move in different } \\
\text { direction (i.e. forward-backward, right left lateral steps, diagonally } \\
\text { backward- forward). }\end{array}$ & $\begin{array}{l}1 \mathrm{~min} \\
30 \mathrm{~s}\end{array}$ \\
\hline
\end{tabular}


The proprioceptive training will include a series of exercises to be performed with eyes opened and eyes closed on a hard surface (floor). Progression of each exercise will be achieved by increasing the duration and number of repetitions as the participant becomes more stable. However, the exercise will be discontinued if the patient reports an exacerbation of symptoms. The exercises are as follows; single-leg balance, blind advanced single-leg balance, toe walking and cross-body leg swings.

\section{KBA exercise}

The participants will perform first kinesthesia exercise before balance and then agility exercise. The kinesthetic training include side-stepping, semi tandem walking, and cross over walking. Participants will be instructed to begin with 15 steps and progress to a maximum of 75 steps per exercise. For the balance training, participants will be asked to stand on a foam surface and all exercises will be performed with both lower limbs. The exercise will be progressed based on the participant's ability by starting with the less stressful and challenging ones and increasing the number of repetitions. Static balance exercises will be performed before progressing to dynamic balance exercises. Dynamic balance includes the addition of small, rapid bouncing movements. After learning dynamic balance activities, progression will be done by therapist perturbing the balance and stimulating neuromuscular mechanism. When a balance exercise continued to prove adequately challenging, the participant will not be asked to progress through different levels of instability. Each participant will perform static and dynamic balance with both limbs and single limb on a foam surface. The exercises will last for 2 minutes. Exercise will be discontinued if the patient reports an exacerbation of symptoms. Finally, the agility training involves multiple changes in direction which will be at a walking pace and progressed by adding more steps or increasing the pace [44]. All exercises will be progressed according to individual's tolerance and abilities within the structure of the program. Number of steps or timing in terms of balance exercises will be reduced for participants who experienced difficulty or increase in pain, but no activity will be eliminated. Thus, the structure of the exercises will be maintained to make it safe and challenging for each participant.

\section{Outcome assessments and follow-ups}

The primary outcomes will be physical function to be measured by Ibadan Knee and Hip Osteoarthritis Outcome Measure (IKHOAM) and quality of life to be measured by Osteoarthritis Knee and Hip Quality of Life Questionnaire (OAKHQOL). The secondary outcomes will be pain intensity to be measured by Visual Analogue Scale (VAS) for pain, knee stability to be measured by Knee Outcome Survey-Activities of Daily Living Scale (KOS-ADLS) and proprioception to be measured using an electrogoniometer. Similar to previous trials on knee OA, if only one knee of the patient is affected, the evaluation of the outcomes will be done for this knee. If the patient has bilateral affectation of which only one meets the ACR criterion [45], only this knee will be evaluated. However, if the patient is having bilateral affectation according to the ACR criterion, the more painful knee will be randomly selected for outcome evaluation. Self-report outcomes not available in Hausa language (i.e. the native language of the majority of the target population) will be translated into Hausa using guidelines for the process of cross-cultural adaptation of self-report measures [49]. This is to ensure that reliable data is collected and participants who are unable to complete English measures are not excluded in the trial $[50,51]$. 
All outcomes will be assessed pre-intervention, immediately post-intervention and at 3-month, 4-month and 6-month post-randomization (Fig. 2). Participants missing their regular appointments will be given makeup appointments until they reach the required sessions for each group. This will be done by contacting them through phone calls. All participants will be advised to refrain from other interventions during the trial except for those taking medications as prescribed by their physician.

\section{Pain intensity}

The Hausa VAS will be used to assess participants' pain severity. It represents the intensity dimension by a $100 \mathrm{~mm}$ plain line with anchor points of "no pain" $(0 \mathrm{~mm})$, "moderated pain" (50 mm), and "worst imaginable pain" (100 mm) [52]. Participants will be asked to rate their current level of pain. The VAS is the most widely used scale for the assessment of pain in clinical settings and it has been reported to be reliable, valid and sensitive in patients with chronic musculoskeletal pain including knee OA [53-56].

\section{Physical function}

The physical function of the participants will be assessed with the Hausa version of the IKHOAM [57]. It contains 33 items with domains consisting of activity limitations, participation restrictions and physical performance tests to assess physical function. The measure is a Nigerian culture and environmentfriendly clinical instrument developed for individuals with knee OA [58]. To obtain the patient's percentage perceived level of physical function, the participant's scores obtained are divided by the total possible score (232) and then multiplied by 100. Lower scores indicate a lower level of physical functioning [58]. The Hausa IKHOAM has been documented to be a reliable and valid measure of physical function in patients with knee OA [57].

\section{Quality of life}

The quality of life of the participants will be measure using the mini OAKHQOL [59]. The questionnaire consists of 20 items derived from the original 40-item questionnaire developed by Rat et al. [60]. The questionnaire consists of five dimensions subscales: physical activities, mental health, pain, social support, and social functioning; and three independent items addressing sexual life, professional life, and fear of being dependent. Each item is measured on a numerical rating scale from 0 to 10 and the mean item score becomes the corresponding dimension score [59]. The mini OAKHQOL has been shown to have good psychometric properties in terms of reliability, validity and factorial structure in subjects with knee and hip OA $[59,61]$.

\section{Knee stability}

Participants' subjective reports of knee stability will be measured with the KOS-ADLS. It is a 14-item questionnaire that assesses symptom-related and specific functional limitations [62]. Six items assess knee symptoms (pain, stiffness, swelling, instability, weakness and limping) and eight items assess functional limitations (walking, stairs ascent/descent, standing, kneeling, squatting, sitting and rising from a sitting position) experienced in the last 1-2 days during the performance of daily activities. Each item is scored on a 6-point Likert scale (0-5 points) [63]. The score is transformed to a $0-100$ point scale 
with the highest score indicating the absence of symptoms and functional limitations [62]. For the purpose of this study, only item pertaining to knee instability symptoms will be evaluated.

\section{Proprioception}

The participants' knee proprioceptive range of motion will be measured using an electrogoniometer (Ergotest Technology, Norway; range: $15-320^{\circ}$ ). The use of electrogoniometer for measuring the relative position of the knee joint has ben has been shown to be a reliable method for assessing joint proprioception [64]. To measure the proprioceptive range of motion, the participants will be asked to wear shorts for ease of attachment of the electrogoniometer to the knee joint [65]. The participants' eyes will be blinded to eliminate visual feedback. They will be asked to sit on a high plinth with the hip at an angle of 80 degrees flexion in such a way that the distal hamstrings and knee joint are hanging freely at a resting position of 85 degrees knee flexion. A thin foam will be wrapped around the tested knee to minimize cutaneous sensation feedback from the attachment of the electrogoniometer [66]. While keeping the knee in neutral position, the electrogoniometer will be placed on the lateral side of the knee joint and its axis coinciding with the flexion/extension axis of the knee [67]. The goniometer will be kept in place using an elastic strap wrapped around the cushion padding. Participants will be instructed to bend the knee to a resting position of $85^{\circ}$ of flexion and in this position they will be instructed to bend from resting position to the Target Angle (TA) of 70 degrees and hold there for 5 seconds, then return back to the resting position (85 degrees of flexion) $[68,69]$. The participants will be then asked to repeat the procedure of bending the knee from the resting position of 85 degrees and say 'YES' on perceiving they reached the target position of $70^{\circ}$ and hold. This angle is will be noted on the electrogoniometer and documented as the Perceived Angle (PA). The difference between TA and PA is the Absolute Angular Error (AAE) which will be documented [68]. This procedure will be repeated three times and the average of the three readings will be calculated and recorded as the error for each participant [64]. The inter-rater (between assessors) and intra-rater (within assessors) reliability of the electrogoniometer used in the present study will be evaluated.

\section{Adverse events}

All participants will be informed during recruitment the possibility of experiencing common adverse events related to exercise interventions such as muscle pull, soreness or cramp. They will be educated that these symptoms are temporary and self-limiting. Nonetheless, in case of any serious adverse events such as exacerbating joint pain, discernible joint swelling, excessive fatigue, light-headedness, angina and shortness of breath or dizziness, they will be advised to contact or report such events immediately to the primary investigator or treating therapist at the study center for prompt action.

\section{Sample size estimation}

Considering the minimal clinically important difference (MCID) of 12.8 points reported for the IKHOAM [70], the sample size was calculated a priori, to detect 12.8 points after intervention, and between-group (between group 1 and group 2 or group 3) difference of 3.0 points, assuming a standard deviation (SD) of 5.0 points, an effect size of 0.29 ; a statistical power of $80 \%$; an alpha of $5 \%$ and a two-tailed $t$-test. The 
calculations suggested a sample size of 75 will be needed. However, while anticipating a $10 \%$ attrition rate $(n=8)$, a total sample size of 84 will be needed with 28 participants per group (three groups). The calculations were performed with the G-power 3.1.9.2 software (University of Dusseldorf, Dusseldorf, Germany) [71].

\section{Statistical analysis}

The statistical analysis will be conducted by an independent statistician who will be blinded to the study procedures. The normality test of the data will be verified with the Shapiro-Wilk test. Per protocol analysis will be considered in which data of participants who completed the study as planned will only be included in the analysis. Descriptive statistics of mean and standard deviation will be used to summarize all continuous variables while frequency and percentages will be used to summarize all categorical variables. Baseline continuous variables will be compared among the three groups using one-way analysis of variance (ANOVA) (for parametric data) or Kruskal-Wallis (for non-parametric data) test. Baseline categorical variables will be compared among the three groups using Chi-square (for cells count more than 5 ) or Fisher's exact (for cells count less than 5 ) test. Mixed between-within subject ANOVA ( $3 \times$ 3 design) will be used to assess interaction effect (change over time), main effects for time (withingroups changes over time), and between-subjects effect (differences between groups) if the data is parametric. Friedman's ANOVA and Kruskal-Wallis test will be used to analyze within-group changes and between-group differences, respectively in all the outcomes when the data follows the non-parametric distribution. Post-hoc analysis will be considered for any significant within- or between-group differences observed. Effects size will be also computed to determine the magnitude of change in outcomes. All data will be analyzed using SPSS version 23 (IBM Co., Armonk, NY, USA) at an alpha level of 0.05 .

\section{Data management}

After baseline assessment, all participants will be recognized only by their initials and numbers. Data will be stored using paper file, computer hard drive, and electronically to have back up copy. All data values will be double-checked by assessors to check for errors and missing values before analysis.

\section{Dissemination}

The results of this study will be submitted for publication to an international peer-reviewed journal irrespective of whether the results are positive, negative or inconclusive.

\section{Discussion}

There is evidence to suggest that proprioceptive and kinaesthetic impairment are present in individuals with knee $\mathrm{OA}$ and that neuromuscular training targeting proprioception, kinaesthesia, balance and agility may be beneficial in addressing these impairments [37, 38, 41, 43]. While PR and KBA exercises have been tested as stand-alone interventions among knee OA patients with satisfactory results, however, studies testing their combination effects in stepped approach using RCT are lacking. Furthermore, the ideal dosage of knee OA exercise-based intervention to achieve the highest effectiveness needs to be 
established to reshape clinical practice. This study will be, therefore, designed to determine the effects of 8 weeks of combined PR and KBA program with different frequency of treatment sessions (i.e. twice weekly or thrice weekly) on physical function, quality of life, pain, knee stability and proprioception in adults with knee OA. The outcomes will be evaluated at 3-month (12 weeks), 4-month (16 weeks) and 6month (24 weeks) after randomization. We hope to follow-up the patients for a year if the 6-month followup results suggest this would be useful.

The findings of this study may provide evidence of effectiveness of combined PR and KBA exercise program for individuals with knee $O A$, which may serve as a basis for recommending the use of such multimodal exercise program in the management of knee OA. The study may also provide evidence for the ideal number of sessions of knee OA exercise-based programs to achieve the highest effectiveness which may guide clinical practice and minimize waste of effort.

Potential factors that could account for the limitation of the present study may include the lack of blinding of the treating therapists due to nature of the interventions. Furthermore, because the present study is a multi-center trial employing the services of different treatment therapists with different skills and expertise, we cannot rule out the possibility of differential treatment. However, the assessor blind, three-arm RCT design with concealed allocation can be considered as the strength of our study.

\section{Trial Status}

Recruitment of participants is on-going since February 2018 and expected to be completed by June 2021 (PACTR201810713260138, registered on 28 November 2017). However, due to the current Covid-19 pandemic, recruitment may not be completed until December 2021.

\section{Ethics approval and consent to participate}

This study got ethical approval from the Health Research Ethics Committee, of Ministry of Health, Kano State (MOH/Off/797/T.I./600), Aminu Kano Teaching Hospital (AKTH), Kano State (MAC/SUB/12A/P3/VI/2279) and National Orthopaedic Hospital Dala (NOHD), Kano State (NOHDK/RET/ETHIC/60). Written, informed consent was obtained from all participants prior to participating in the study. Any justifiable modifications to this protocol will be communicated to the Health Research Ethics Committee of the Kano State Ministry of Health, AKTH and NOHD as well as updated in the Pan African Clinical Trials Registry (PACTR201810713260138).

\section{Consent for publication}

Not applicable.

\section{Availability of data and materials}

The full protocol for the study will be made available by the corresponding author on request. 


\section{Abbreviations}

AAE

Absolute Angular Error; ACR:American College of Rheumatology; AKTH:Aminu Kano Teaching Hospital; ANOVA:Analysis of variance; IKHOAM:Ibadan Knee and Hip Osteoarthritis Outcome Measure;

KBA:Kinesthesia, balance and agility; KOS-ADLS:Knee Outcome Survey-Activities of Daily Living Scale; MAWTH:Muhammad Abdullahi Wase Teaching Hospital; MCID:Minimal clinically important difference; MMSH:Murtala Muhammad Specialist Hospital; NOHD:National Orthopedic Hospital Dala; PA:Perceived angle; PACTR:Pan African Clinical Trials Registry; PR:Proprioceptive; OA:Osteoarthritis;

OAKHQOL:Osteoarthritis Knee and Hip Quality of Life Questionnaire; RCT:Randomized controlled trial; SPIRIT:Standard Protocol Items:Recommendations for Interventional Trials; TA:Target angle; UST:Ultrasound therapy; VAS:Visual Analogue Scale

\section{Declarations}

\section{Ethics approval and consent to participate}

This study got ethical approval from theHealth Research Ethics Committee, of Ministry of Health, Kano State (MOH/Off/797/T.I./600), Aminu Kano Teaching Hospital (AKTH), Kano State (MAC/SUB/12A/P3/VI/2279) and National Orthopaedic Hospital Dala (NOHD), Kano State (NOHDK/RET/ETHIC/60).Written, informed consent was obtained from all participants prior to participating in the study. Any justifiable modifications to this protocol will be communicated to the Health Research Ethics Committee of the Kano State Ministry of Health, AKTH and NOHD as well as updated in the Pan African Clinical Trials Registry(PACTR201810713260138).

\section{Consent for publication}

Not applicable.

\section{Availability of data and materials}

The full protocol for the study will be made available by the corresponding author on request.

\section{Competing interests}

The authors declare that they have no competing interests.

\section{Funding}


This research received no grant from any funding agency.

\section{Authors' contributions}

AIA is the Principal Investigator. AIA, MOA and AAI conceived the study. AIA and AAI developed the first draft of the protocol. AAl reviewed and edited the protocol. MOA supervised the protocol. AAl proposed the statistical analyses. All authors contributed to the trial design. All authors have read, contributed to, and approved the final manuscript.

\section{Acknowledgments}

We would like to thank the entire physiotherapists who will be assisting in the recruitment, assessment and treatment of patients in this study. We also acknowledge the head of physiotherapy department of Muhammad Abdullahi Wase Teaching Hospital, Murtala Muhammad Specialist Hospital, Aminu Kano Teaching Hospital and National Orthopaedic Hospital, Dala for their valuable support.

\section{References}

1. Shane Anderson A, Loeser RF. Why is osteoarthritis an age-related disease? Best Pract Res Clin Rheumatol. 2010;24(1):15-26.

2. Charlesworth J, Fitzpatrick J, Perera NKP, Orchard J. Osteoarthritis- a systematic review of long-term safety implications for osteoarthritis of the knee. BMC Musculoskelet Disord. 2019;20(1):151.

3. Hunter DJ, Bierma-Zeinstra S. Osteoarthritis Lancet. 2019;393(10182):1745-59.

4. Litwic A, Edwards MH, Dennison EM, Cooper C. Epidemiology and burden of osteoarthritis. Br Med Bull. 2013;105:185-99.

5. Silverwood V, Blagojevic-Bucknall M, Jinks C, Jordan JL, Protheroe J, Jordan KP. Current evidence on risk factors for knee osteoarthritis in older adults: a systematic review and meta-analysis. Osteoarthritis Cartilage. 2015;23(4):507-15.

6. Chu CR, Millis MB, Olson SA. Osteoarthritis. From Palliation to Prevention: AOA Critical Issues. J Bone Joint Surg Am. 2014;96(15):e130.

7. Vos T, Flaxman AD, Naghavi M, Lozano R, Michaud C, Ezzati M, et al. Years lived with disability (YLDs) for 1160 sequelae of 289 diseases and injuries 1990-2010: a systematic analysis for the Global Burden of Disease Study 2010. Lancet. 2012;380(9859):2163-96.

8. Deshpande BR, Katz JN, Solomon DH, Yelin EH, Hunter DJ, Messier SP, et al. Number of Persons With Symptomatic Knee Osteoarthritis in the US: Impact of Race and Ethnicity, Age, Sex, and Obesity. Arthritis Care Res. 2016;68(12):1743-50.

9. Usenbo A, Kramer V, Young T, Musekiwa A. Prevalence of Arthritis in Africa: A Systematic Review and Meta-Analysis. PLoS One. 2015;10(8):e0133858. 
10. Akinpelu AO, Alonge TO, Adekanla BA, Odole AC. Prevalence and pattern of symptomatic knee osteoarthritis in Nigeria: A community-based study. Internet J Allied Health Sci Pract. 2009;7(3):10.

11. Akinpelu A, Maduagwu S, Odele A, Alonge T. Prevalence and pattern of knee osteoarthritis in a North Eastern Nigerian rural community. East Afr Orthop J. 2011;5(1).

12. Ebong WW. Osteoarthritis of the knee in Nigerians. Ann Rheum Dis. 1985;44(10):682-4.

13. Ibrahim D, Borodo M, Adelowo O. Clinical pattern of knee osteoarthritis in patients seen at rheumatology clinic of Aminu Kano Teaching Hospital, Northwestern Nigeria. Afr J Rheum. 2014;2(1):13-7.

14. Akinpelu A, Alonge $O$, Adekanla B, Odole A. Pattern of osteoarthritis seen in physiotherapy facilities in Ibadan and Lagos, Nigeria. Afr J Biomed Res. 2007;10(2):111-5.

15. Adebusoye L, Ogunbode A, Alonge T. Magnitude of knee osteoarthritis and associated risk factors among adult patients presenting in a family practice clinic in Nigeria. Journal of Medicine in the Tropics. 2013;15(2):144-50.

16. Greene MA, Loeser RF. Aging-related inflammation in osteoarthritis. Osteoarthritis Cartilage. 2015;23(11):1966-71.

17. Zhang Y, Jordan JM. Epidemiology of osteoarthritis. Clin Geriatr Med. 2010;26(3):355-69.

18. March LM, Bagga H. Epidemiology of osteoarthritis in Australia. Med J Aust. 2004;180(S5):6-10.

19. Choquette D, Raynauld JP, Rich E. Basic Principles in Osteoarthritis Treatment. In: Reginster JY, Pelletier JP, Martel-Pelletier J, Henrotin Y, Crasborn L, editors. Osteoarthritis: Clinical and Experimental Aspects. Berlin: Springer Berlin Heidelberg; 1999. pp. 356-70.

20. Fransen M, McConnell S, Harmer AR, Van der Esch M, Simic M, Bennell KL. Exercise for osteoarthritis of the knee: a Cochrane systematic review. Br J Sports Med. 2015;49(24):1554-7.

21. Briani RV, Ferreira AS, Pazzinatto MF, Pappas E, De Oliveira Silva D, Azevedo FMd. What interventions can improve quality of life or psychosocial factors of individuals with knee osteoarthritis? A systematic review with meta-analysis of primary outcomes from randomised controlled trials. $\mathrm{Br} \mathrm{J}$ Sports Med. 2018;52(16):1031.

22. Fernandes L, Hagen KB, Bijlsma JW, Andreassen O, Christensen P, Conaghan PG, et al. EULAR recommendations for the non-pharmacological core management of hip and knee osteoarthritis. Ann Rheum Dis. 2013;72(7):1125-35.

23. McAlindon TE, Bannuru RR, Sullivan MC, Arden NK, Berenbaum F, Bierma-Zeinstra SM, et al. OARSI guidelines for the non-surgical management of knee osteoarthritis. Osteoarthritis Cartilage. 2014;22(3):363-88.

24. Kolasinski SL, Neogi T, Hochberg MC, Oatis C, Guyatt G, Block J, et al. 2019 American College of Rheumatology/Arthritis Foundation Guideline for the Management of Osteoarthritis of the Hand, Hip, and Knee. Arthritis Rheum. 2020;72(2):220-33.

25. Brosseau L, Taki J, Desjardins B, Thevenot O, Fransen M, Wells GA, et al. The Ottawa panel clinical practice guidelines for the management of knee osteoarthritis. Part two: strengthening exercise 
programs. Clin Rehabil. 2017;31(5):596-611.

26. Brosseau L, Taki J, Desjardins B, Thevenot O, Fransen M, Wells GA, et al. The Ottawa panel clinical practice guidelines for the management of knee osteoarthritis. Part three: aerobic exercise programs. Clin Rehabil. 2017;31(5):612-24.

27. Brosseau L, Taki J, Desjardins B, Thevenot O, Fransen M, Wells GA, et al. The Ottawa panel clinical practice guidelines for the management of knee osteoarthritis. Part one: introduction, and mind-body exercise programs. Clin Rehabil. 2017;31(5):582-95.

28. Goh S-L, Persson MSM, Bhattacharya A, Hall M, Doherty M, Zhang W. Relative efficacy of different types of exercise for treatment of knee and hip osteoarthritis: protocol for network meta-analysis of randomised controlled trials. Syst Rev. 2016;5(1):147.

29. Smith TO, King JJ, Hing CB. The effectiveness of proprioceptive-based exercise for osteoarthritis of the knee: a systematic review and meta-analysis. Rheumatol Int. 2012;32(11):3339-51.

30. Lephart SM. Proprioception and neuromuscular control in joint stability. Human Kinetics. 2000:40513.

31. Sharma L. Proprioceptive impairment in knee osteoarthritis. Rheum Dis Clin North Am. 1999;25(2):299-314. vi.

32. Felson DT, Gross KD, Nevitt MC, Yang M, Lane NE, Torner JC, et al. The effects of impaired joint position sense on the development and progression of pain and structural damage in knee osteoarthritis. Arthritis Rheum. 2009;61(8):1070-6.

33. Lund H, Juul-Kristensen B, Hansen K, Christensen R, Christensen H, Danneskiold-Samsoe B, et al. Movement detection impaired in patients with knee osteoarthritis compared to healthy controls: a cross-sectional case-control study. J Musculoskelet Neuronal Interact. 2008;8(4):391-400.

34. Sekir U, Gür H. A multi-station proprioceptive exercise program in patients with bilateral knee osteoarthrosis: functional capacity, pain and sensoriomotor function. A randomized controlled trial. J Sports Sci Med. 2005;4(4):590-603.

35. Lin $\mathrm{DH}$, Lin $\mathrm{CH}$, Lin YF, Jan MH. Efficacy of 2 non-weight-bearing interventions, proprioception training versus strength training, for patients with knee osteoarthritis: a randomized clinical trial. J Orthop Sports Phys. 2009;39(6):450-7.

36. Jan MH, Tang PF, Lin JJ, Tseng SC, Lin YF, Lin DH. Efficacy of a target-matching foot-stepping exercise on proprioception and function in patients with knee osteoarthritis. J Orthop Sports Phys Ther. 2008;38(1):19-25.

37. Mondam S, Srikanth Babu V, Raviendra Kumar B, Prakash J. A Comparative Study of Proprioceptive Exercises versus Conventional Training Program on Osteoarthritis of Knee. Res J Recent Sci. 2012;1(12):31-5.

38. Gomiero AB, Kayo A, Abraão M, Peccin MS, Grande AJ. Sensory-motor training versus resistance training among patients with knee osteoarthritis: randomized single-blind controlled trial. Sao Paulo Med J. 2018;136(1):44-50. 
39. Jeong HS, Lee SC, Jee H, Song JB, Chang HS, Lee SY. Proprioceptive Training and Outcomes of Patients With Knee Osteoarthritis: A Meta-Analysis of Randomized Controlled Trials. J Athl Train. 2019;54(4):418-28.

40. Anwer S, Alghadir A, Brismée JM. Effect of Home Exercise Program in Patients With Knee Osteoarthritis: A Systematic Review and Meta-analysis. J Geriatr Phys Ther. 2016;39(1):38-48.

41. Rogers MW, Tamulevicius N, Coetsee MF, Curry BF, Semple SJ. Knee Osteoarthritis and the Efficacy of Kinesthesia, Balance \& Agility Exercise Training: A Pilot Study. Int J Exerc Sci. 2011;4(2):124-32.

42. Fitzgerald GK, Piva SR, Gil AB, Wisniewski SR, Oddis CV, Irrgang JJ. Agility and perturbation training techniques in exercise therapy for reducing pain and improving function in people with knee osteoarthritis: a randomized clinical trial. Phys Ther. 2011;91(4):452-69.

43. Diracoglu D, Aydin R, Baskent A, Celik A. Effects of kinesthesia and balance exercises in knee osteoarthritis. J Clin Rheumatol. 2005;11(6):303-10.

44. Rogers MW, Tamulevicius N, Semple SJ, Krkeljas Z. Efficacy of home-based kinesthesia, balance \& agility exercise training among persons with symptomatic knee osteoarthritis. J Sports Sci Med. 2012;11(4):751-8.

45. Altman R, Asch E, Bloch D, Bole G, Borenstein D, Brandt K, et al. Development of criteria for the classification and reporting of osteoarthritis. Classification of osteoarthritis of the knee. Diagnostic and Therapeutic Criteria Committee of the American Rheumatism Association. Arthritis Rheum. 1986;29(8):1039-49.

46. Chaipinyo K, Karoonsupcharoen $\mathrm{O}$. No difference between home-based strength training and homebased balance training on pain in patients with knee osteoarthritis: a randomised trial. Aust J Physiother. 2009;55(1):25-30.

47. Loew L, Brosseau L, Wells GA, Tugwell P, Kenny GP, Reid R, et al. Ottawa panel evidence-based clinical practice guidelines for aerobic walking programs in the management of osteoarthritis. Arch Phys Med Rehabil. 2012;93(7):1269-85.

48. Lundebjerg $\mathrm{N}$. Exercise prescription for older adults with osteoarthritis pain: consensus practice recommendations. J Am Geriatr Soc. 2001;49(6):808-23.

49. Beaton DE, Bombardier C, Guillemin F, Ferraz MB. Guidelines for the process of cross-cultural adaptation of self-report measures. Spine. 2000;25(24):3186-91.

50. Ibrahim AA, Akindele MO, Bello B, Kaka B, Translation. Cross-cultural Adaptation, and Psychometric Properties of the Hausa Versions of the Numerical Pain Rating Scale and Global Rating of Change Scale in a Low-literate Population With Chronic Low Back Pain. Spine. 2020;45(8):E439-e47.

51. Adamu AS, Ibrahim AA, Rufa'i YA, Akindele MO, Kaka B, Mukhtar NB. Cross-cultural Adaptation and Validation of the Hausa Version of the Oswestry Disability Index 2.1 a for Patients With Low Back Pain. Spine. 2019;44(18):E1092-E102.

52. Odole AC, Akinpelu AO. Translation and alternate forms reliability of the Visual Analogue Scale in the three major Nigerian languages. Internet J Allied Health Sci Pract. 2009;7(3):13. 
53. Boonstra AM, Schiphorst Preuper HR, Reneman MF, Posthumus JB, Stewart RE. Reliability and validity of the visual analogue scale for disability in patients with chronic musculoskeletal pain. Int $\mathrm{J}$ Rehabil Res. 2008;31(2):165-9.

54. Alghadir AH, Anwer S, lqbal A, Iqbal ZA. Test-retest reliability, validity, and minimum detectable change of visual analog, numerical rating, and verbal rating scales for measurement of osteoarthritic knee pain. J Pain Res. 2018;11:851-6.

55. Bellamy N, Campbell J, Syrotuik J. Comparative study of self-rating pain scales in osteoarthritis patients. Curr Med Res Opin. 1999;15(2):113-9.

56. Joyce CRB, Zutshi DW, Hrubes V, Mason RM. Comparison of fixed interval and visual analogue scales for rating chronic pain. Europ J Clin Pharmacol. 1975;8(6):415-20.

57. Odole AC, Akinpelu AO. Validity and internal consistency of a Hausa version of the Ibadan Knee/Hip Osteoarthritis Outcome Measure. Health Qual Life Outcomes. 2008;6:86.

58. Odole AC, Odunaiya NA, Akinpelu AO. Ibadan knee/hip osteoarthritis outcome measure: process of development. Ann Ib Postgrad Med. 2013;11(2):71-6.

59. Guillemin F, Rat AC, Goetz C, Spitz E, Pouchot J, Coste J. The Mini-OAKHQOL for knee and hip osteoarthritis quality of life was obtained following recent shortening guidelines. J Clin Epidemiol. 2016;69:70-8.

60. Rat AC, Pouchot J, Coste J, Baumann C, Spitz E, Retel-Rude N, et al. Development and testing of a specific quality-of-life questionnaire for knee and hip osteoarthritis: OAKHQOL (OsteoArthritis of Knee Hip Quality Of Life). Joint Bone Spine. 2016;73(6):697-704.

61. Gonzalez Saenz de Tejada M, Bilbao A, Herrera C, Garcia L, Sarasqueta C, Escobar A. Validation of the Mini-OAKHQOL for use in patients with osteoarthritis in Spain. Clin Rheumatol. 2017;36(8):185564.

62. Irrgang JJ, Snyder-Mackler L, Wainner RS, Fu FH, Harner CD. Development of a patient-reported measure of function of the knee. J Bone Joint Surg Am. 1998;80(8):1132-45.

63. Roy JS, Esculier JF, Maltais DB. Translation, cross-cultural adaptation and validation of the French version of the Knee Outcome Survey-Activities of Daily Living Scale. Clin Rehabil. 2014;28(6):61423.

64. Olsson L, Lund H, Henriksen M, Rogind H, Bliddal H, Danneskiold-Samsøe B. Test-retest reliability of a knee joint position sense measurement method in sitting and prone position. Adv Physiother. 2004;6(1):37-47.

65. Piriyaprasarth P, Morris ME, Winter A, Bialocerkowski AE. The reliability of knee joint position testing using electrogoniometry. BMC Musculoskelet Disord. 2008;9:6.

66. Larsen R, Lund H, Christensen R, Røgind H, Danneskiold-Samsøe B, Bliddal H. Effect of static stretching of quadriceps and hamstring muscles on knee joint position sense. Br J Sports Med. 2005;39(1):43-6.

67. Gerhardt JJ. Documentation of Joint Motion: International Standard Neutral-zero Measuring, SFTR Recording and Application of Goniometers. Inclinometers: Isomed; 1996. 
68. Pradeep T, Solomen S, Aaron P. The influence of dynamic stretch of quadriceps, hamstrings and its combined stretch effect on knee joint position sense (JPS) in healthy adults. Int J Multidiscip Res Dev. 2016;3(7):50-4.

69. Han J, Waddington G, Adams R, Anson J, Liu Y. Assessing proprioception: a critical review of methods. J Sport Health Sci. 2016;5(1):80-90.

70. Akinpelu AO, Odole AC, Raheem S. Minimal clinically important difference of Ibadan knee hip osteoarthritis outcome measure (IKHOAM) a cross-sectional study. J Phys Ther. 2011;3:52-60.

71. Faul F, Erdfelder E, Lang AG, Buchner A. G*Power 3: a flexible statistical power analysis program for the social, behavioral, and biomedical sciences. Behav Res Methods. 2007;39(2):175-91.

\section{Figures}




\begin{tabular}{|c|c|c|c|c|c|c|c|}
\hline & \multicolumn{7}{|c|}{ STUDY PERIOD } \\
\hline & $\begin{array}{l}\text { Before start } \\
\text { of } \\
\text { intervention }\end{array}$ & Baseline & $\begin{array}{l}\text { Intervention over } \\
8 \text { weeks }\end{array}$ & $\begin{array}{l}\text { Post- } \\
\text { intervention }\end{array}$ & \multicolumn{3}{|c|}{$\begin{array}{c}\text { Follow-up } \\
\text { (post-randomization) }\end{array}$} \\
\hline TIME POINT & $-t_{1}$ & 0 & & $t_{4}$ & $\begin{array}{l}3 \text { months } \\
\text { after } 0\end{array}$ & $\begin{array}{l}4 \text { months } \\
\text { after } 0\end{array}$ & $\begin{array}{l}6 \text { months } \\
\text { after } 0\end{array}$ \\
\hline ENROLMENT: & & & & & & & \\
\hline Ethical approval & $\mathrm{x}$ & & & & & & \\
\hline Trial registration & $\mathrm{x}$ & & & & & & \\
\hline Eligibility screening & $\mathrm{x}$ & & & & & & \\
\hline Informed consent & $\mathrm{x}$ & & & & & & \\
\hline Baseline questionnaires & & $\mathrm{x}$ & & & & & \\
\hline R andomization & & $\mathrm{x}$ & & & & & \\
\hline INTE RVE NTION S: & & & & & & & \\
\hline $\begin{array}{r}\text { Conventional } \\
\text { phys iotherapy (group 1) }\end{array}$ & & & & $\mathrm{x}$ & & & \\
\hline $\begin{array}{r}\text { Two sessions per week of } \\
\text { combined PR and } K B A \\
\text { exerc ise (group 2) }\end{array}$ & & & & $\mathrm{x}$ & & & \\
\hline $\begin{array}{r}\text { Three sess ions perweek } \\
\text { of combined PR and } K B A \\
\text { exerc ise (group } 3 \text { ) }\end{array}$ & & & & $x$ & & & \\
\hline AS SE SSME NTS: & & & & & & & \\
\hline $\begin{array}{l}\text { Socio-demographic and } \\
\text { clinical characteristics }\end{array}$ & & $x$ & & & & & \\
\hline $\begin{array}{r}\text { IKHOAM(physical } \\
\text { function) } \\
O A K H Q O L \text { (quality of life) }\end{array}$ & & $x$ & & $x$ & $x$ & $x$ & $x$ \\
\hline $\begin{array}{r}\text { VAS (pain intens ity) } \\
\text { KOS-ADLS (knee stability) } \\
\text { Electrogoniometer } \\
\text { (proprioception) }\end{array}$ & & $\mathrm{x}$ & & $\mathrm{x}$ & $\mathrm{x}$ & $\mathrm{x}$ & $\mathrm{x}$ \\
\hline
\end{tabular}

$P R$, proprioceptive exerc ise; KBA, kines thes ia, balance and agility ex ercise; IKHOAM, Ibadan Knee and Hip Os teoarthritis Outcome Measure; OAKHQOL, Osteoarthritis Knee and Hip Quality of Life Questionnaire; VAS, Visual Analogue Scale; Knee Outc omes Survev-Activities of Dailv Livinq Scale, KOS-ADLS

Figure 1

Outline of the study design 


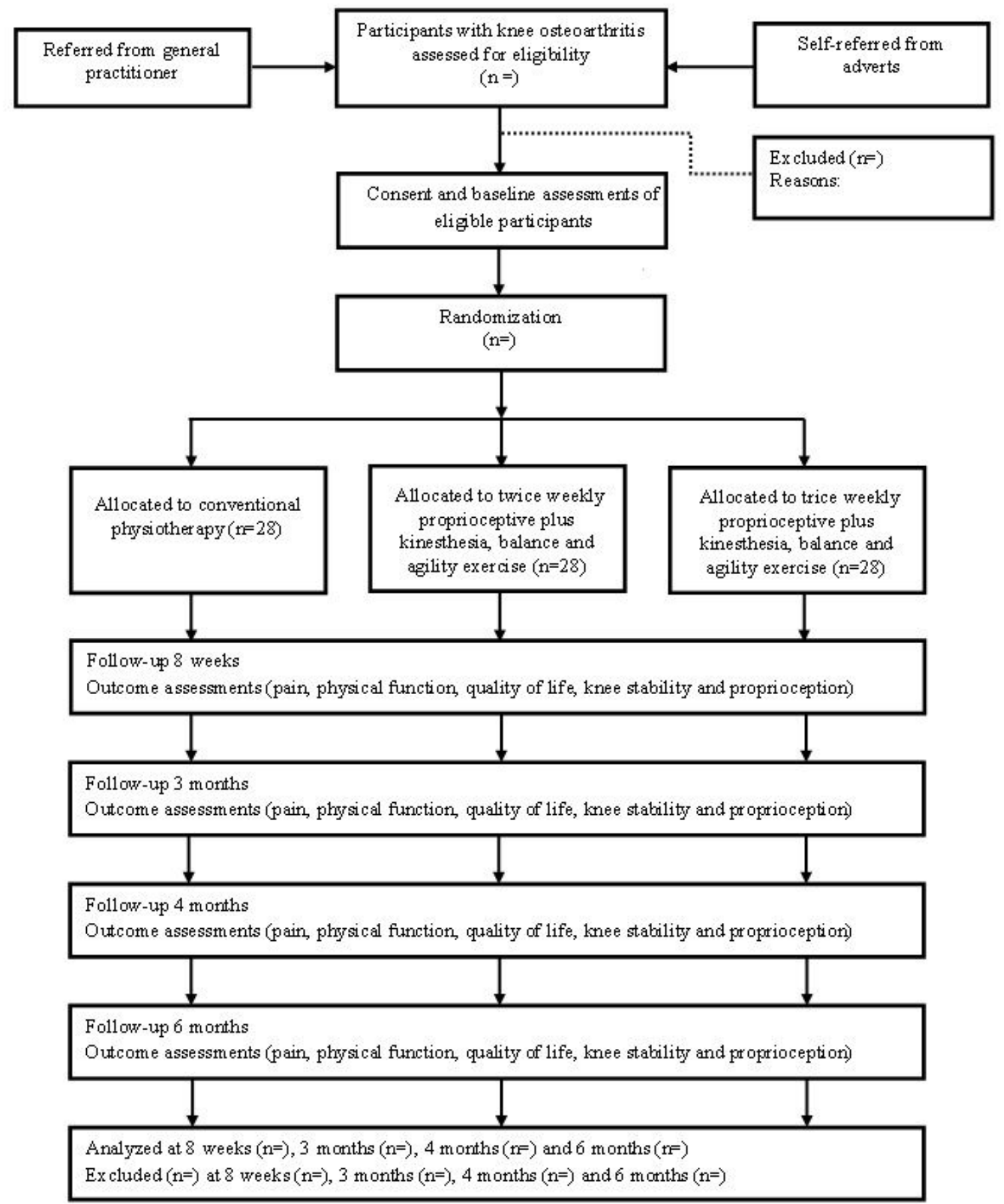

\section{Figure 2}

Flow of participants through the study

\section{Supplementary Files}

This is a list of supplementary files associated with this preprint. Click to download. 
- SPIRITChecklistAppendix1.docx

- HREC.pdf

- Researchfunding.docx 